\title{
El modelo autonómico y nuevas formas de identidad. Antecedentes para un equilibrio de futuro
}

\author{
Gonzalo Herranz de Rafael \\ Universidad de Almería \\ gherranz@ual.es
}

\section{Resumen}

Análisis teórico y empírico del concepto de identidad a partir de su aplicación sobre las formas de identificación territorial surgidas como consecuencia de la instauración del modelo autonómico de distribución territorial del poder en España.

Los datos vienen a corroborar la hipótesis de partida: en España predomina un relativismo territorial que se traduce en un mestizaje identitario que explica suficientemente por qué más de la mitad de los españoles se sienten y asumen una identificación dual o nacionalidad compartida con España y su Comunidad Autónoma.

Palabras clave: identidad, modelo autonómico, identificación dual, nacionalidad compartida.

Abstract. The autonomous pattern and new forms of identity. Antecedents for a future balance

Theoretical and empiric analysis of the concept of identity starting from their application on the forms of territorial identification arisen as consequence of the setting-up of the autonomous pattern of territorial distribution of the power in Spain.

The data come to corroborate the departure hypothesis: in Spain a territorial relativism that it translates himself in a crossbreeding of identity that it explains the sufficiently prevails why more than half of the Spaniards they feel and they assume a dual nationality or a shared nationalism with Spain and its Autonomous Community.

Key words: identity, autonomous pattern, dual nationality, shared nationalism.

\section{Sumario}

Introducción

1. El concepto de identidad: génesis, estructura y conflicto en los ámbitos individual y colectivo

2. Metodología e hipótesis
3. Análisis de los resultados

Conclusiones

Bibliografía 


\section{Introducción}

Este trabajo trata sobre el concepto de identidad, tanto en su esfera individual como colectiva y, dentro de este último aspecto, del sentimiento que vincula a los individuos con su ámbito territorial surgido a partir de la implantación del modelo del Estado de las Autonomías o sistema autonómico, cuya idiosincrasia ha hecho posible que surjan nuevas formas de interpretar lo que se podría denominar, en términos genéricos, la «identidad nacional».

$\mathrm{El}$ análisis se realiza en dos niveles: en el primero, y desde una perspectiva teórica, daremos una interpretación de la identidad en su génesis, estructura y alcance, tanto individual como colectivamente; en el segundo, profundizaremos en las nuevas formas de identificación que posibilita este modelo, en especial la denominada «dual» o «nacionalidad compartida» ${ }^{1}$. Creemos que esta nueva forma de vinculación con España es el referente demostrativo de la vigencia y validez del modelo autonómico.

Para ello, utilizaremos datos primarios procedentes de encuestas llevadas a cabo por el CIRES en la década de 1990 en España, esencialmente por dos motivos: el primero, por ser considerada una década clave en la consolidación de la identidad compartida y, el segundo, porque metodológicamente se ha podido disponer de datos históricos homogéneos que han posibilitado un más certero análisis de la realidad ${ }^{2}$.

1. Smith, uno de los teóricos más importantes del nacionalismo y de las identidades colectivas en general, establece como lógica la nacionalidad compartida en determinados contextos territoriales y por determinados movimientos nacionalistas: «los movimientos de autonomía étnica admiten la posibilidad, quizás la conveniencia, de la identidad dual, una identidad nacional-cultural y una nacional-política o, como ellos lo contemplarían, una identidad nacional dentro de una identidad estatal territorial: [...] una nación catalana en España, etc., admiten la dualidad de recuerdos históricos y sentimientos políticos que no pueden ser separados con facilidad, por no hablar de las ventajas económicas que conlleva la permanencia en el marco de un Estado que ya existe», en SMITH, A. D. (1997). La identidad nacional. Madrid: Trama, p. 126-127.

2. Metodológicamente, los datos que hemos utilizado del CIRES son determinantes, en el sentido de poder disponer de datos primarios continuos durante cinco años para analizar determinadas variables que no han sido utilizadas con la misma regularidad por otras instituciones como el CIS, además de que ésta última en ocasiones no ha utilizado la misma pregunta o escala, como son: la escala del sentimiento nacionalista; la confianza en el Gobierno de España, la Comunidad Autónoma y la Unión Europea; el orgullo hacia España como país, el orgullo hacia la Comunidad Autónoma, y el grado de identificación con España, con la Comunidad Autónoma y con la Unión Europea. Respecto a la escala del sentimiento nacionalista, el CIS la incluye en determinadas encuestas, aunque en muchos casos no aplicadas a nivel nacional, o la incluye en estudios concretos, pero, por ejemplo, no la incluye en el barómetro mensual. Así, la encontramos, por no irnos mucho más atrás en el tiempo, en el estudio número 2.257 sobre «Juventud e identidad nacional», de septiembre de 1997; en el número 2.286 sobre "Instituciones y autonomía (I)», del 5 de mayo de 1998, no disponible en la página web del CIS; en el número 2.304 sobre la «Preelectoral del País Vasco», de septiembre de 1998; en el número 2.308 sobre la «Postelectoral del País Vasco de las elecciones autonómicas de 1998», de octubre-noviembre de 1998; en el número 2.319 sobre la "Situación social y política de la Comunidad Valenciana", de febreromarzo de 1999; en el número 2.373 sobre la "Preelectoral de Cataluña de las elecciones 


\section{El concepto de identidad: génesis, estructura y conflicto en los ámbitos individual y colectivo}

Partiendo del hecho de que toda identidad es una construcción social ${ }^{3}$, la mayoría de ellas están creadas, organizadas y difundidas ${ }^{4}$ por una intelligentsia, mino-

autonómicas de 1999», de septiembre-octubre de 1999; en el número 2.374 sobre la «Postelectoral de Cataluña, de la elecciones autonómicas de 1999", de octubre-noviembre de 1999; en "Dato de Opinión de Estudios del CIS», número 2.421, de mayo de 2001, y en el número 2.434, de octubre de 2001, boletín número 28, de enero-abril de 2002; en el número 2.413 sobre la «Situación social y política de la Comunidad Valenciana VII», de marzo-abril de 2001; en el número 2.445 sobre el «Estudio sociológico de la Comunidad Valenciana", de febrero de 2002; en el número 2.450 sobre "Ciudadanía, participación y democracia», de febrero de 2002, y el más reciente, en el boletín número 31, sobre "Instituciones y autonomía», de enero-abril de 2003, aunque en este caso la escala ha sido aplicada por Comunidades Autónomas. Para el caso del orgullo, ocurre algo parecido: no tiene ninguna continuidad en las diferentes encuestas y casi siempre es referido a España y en muy contadas ocasiones, a las Comunidades Autónomas. Por ejemplo, en el único caso donde aparecen ambas es en el número 2.257 sobre «Juventud e identidad nacional», de septiembre de 1997. El resto es sólo para el caso de España: número 2.270, «Latinobarómetro II», de diciembre de 1997; número 2.317 sobre «La defensa nacional y la profesionalización del ejército III», de febrero de 1999; número 2.417 sobre el «Latinobarómetro IV», de mayo de 2001; número 2.476 sobre el «Latinobarómetro de 2003»; número 2.571 sobre el «Latinobarómetro VII», de septiembre de 2004. Lo mismo podría argumentarse respecto al grado de identificación con la Unión Europea, donde el CIS ha utilizado en sus barómetros una escala diferente (la pregunta dice: «En la actualidad, Ud. se siente: 1 . Sobre todo ciudadano europeo; 2 . Sobre todo ciudadano español; 3. Ciudadano europeo y ciudadano español al mismo tiempo; 4. Ninguna de las respuestas anteriores; 5 . No sabe; 6 . No contesta») y con escasa continuidad: número 2.339, barómetro de mayo de 1999, de la Unión Europea; número 2.392, barómetro de mayo de 2000 de la Unión Europea, y, el último, número 2.595, postreferéndum sobre la Constitución europea, febrero-marzo de 2005.

3. Por ejemplo, desde una perspectiva individual, Giddens define la identidad del yo como "una conciencia refleja...» o, más concretamente, «Es el yo entendido reflexivamente por la persona en función de su biografía», en GIDDENS, A. (1995), Modernidad e identidad del yo, Barcelona: Península, p. 72. Morin, en cambio, define la identidad del yo en la relación intersubjetiva con el sujeto, «reconoce el carácter originario cuasi simultáneo de la autoafirmación del yo y de su relación con el otro», en Morin, E. (2003), El método. La humanidad de la humanidad. La identidad humana, Madrid: Cátedra, p. 86.

4. Para el caso de una de las identidades colectivas como es el nacionalismo, hay una amplia mayoría de analistas del mismo que están de acuerdo en afirmar que la intelligentsia es la que verdaderamente crea, organiza y difunde la conciencia nacionalista, considerándose la verdadera impulsora de gran parte de los partidos y movimientos nacionalistas. En este sentido, véase, por ejemplo, RovIRA Y VIRGILI, A. (1980), Historia de los movimientos nacionalistas, 3 vols., Barcelona: Herder; GELLNER, E. (1988), Naciones y nacionalismo, Madrid: Alianza; HobSBAWN, E. J. (1992), Naciones y nacionalismos desde 1780, Barcelona: Critica; Herranz, G. (1992), La vigencia del nacionalismo, Madrid: CIS. Hay otros, en cambio, que opinan que esta situación no se cumple. Por ejemplo, entre otros, SMITH, A. D. (1976), Las teorías del nacionalismo, Barcelona: Península; The ethnic origins of nations, Oxford, Blackwell, 1986; RuberT DE Ventós, X. (1994), Nacionalismos. El laberinto de la identidad, Madrid: Espasa-Calpe; Connor apunta que «El nacionalismo es un fenómeno de masas. El hecho de que los miembros de la élite gobernante o de la intelligentsia manifiesten un sentimiento nacional no es fundamento suficiente para deducir que la conciencia nacional ha impregnado el sistema de valores de las masas», 
ría social o élite, con diferentes objetivos para cada uno de los tipos posibles, cuya fundamentación ideológico-doctrinal es posteriormente interiorizada por la mayor parte de la población a través de distintas formas de socialización, y la podemos entender como el proceso mediante el cual el sujeto o los sujetos eligen para llevar a cabo su acción social unos o varios atributos culturales ${ }^{5}$ como referentes primarios y formas de distinción, tanto individual como colectiva.

Lógicamente, partimos de una concepción de la cultura muy cercana a la establecida por Morin, como «herencia social de lo humano, las culturas alimentan las identidades individuales y sociales en la que éstas tienen de específico». Pero, a su vez, «ésta es la razón de que las culturas puedan mostrarse incomprensivas respecto de otras culturas, e incomprensibles entre sí» $^{6}$.

Lógicamente, este tipo de colectivo articula una funcionalidad que estaría en las antípodas de los intereses de las nuevas élites que actúan en el ámbito de la nueva mundialización, y que se concretarían en una nueva ideología que tiende a "despersonalizar y a desresponsabilizar su propia conducta, que le parece que obedece a la racionalidad y a la objetividad. Produce una inteligencia ciega para todo lo que queda fuera del cálculo, y pilota la "mundialización del liberalismo"”, en Morin, E., ob. cit., p. 266. No obstante, aparte de estrategias diversas de ambos colectivos, mantienen un denominador común basado en la articulación de la legitimidad de su poder y autoridad: una mayor información, conocimiento y control de las instancias burocráticas y gestoras y sobre todo una hipereducación especializada. Véase, a este respecto, entre otros, LASCH, C. (1996), La revolución de las élites y traición a la democracia, Barcelona: Paidós. CONNOR, W. (1998), Etnonacionalismo, Madrid: Trama, p. 199-200.

5. Aquí incluimos también los referentes culturales más cotidianos, que, siguiendo a Goytisolo a la hora de valorar cuales pueden formar la naturaleza de los sentimientos de pertenencia, en este caso nacionalista, dice, «Algo, diría yo, que hay que considerar en sentido amplio, relativo no tanto a los principales hitos de la cultura en cuestión cuanto a sus datos más cotidianos, hábitos, maneras, expresiones coloquiales, alusiones implícitas que impregnan la relación de cada uno con los demás y hasta el sentido del humor al uso, rasgos cuya suma define el referente cultural como un asunto de comunicación», en GOYTISOLO, L. (2004), «Referente cultural y sentimiento nacionalista», El Pais, lunes 9 de febrero, p. 12.

6. Morin, E., ob. cit, p. 71. Véase, por ejemplo, como botón de muestra, el relato a modo de observación participante de la novela de Äsne SERIERSTAD (2002), El librero de Kabul, Madrid, Maeva, cuando especifica: «Sin embargo, rara vez en mi vida me he enfadado tanto con alguien, rara vez he discutido tanto con alguien y nunca he tenido tantas ganas de pegar a alguien como mi estancia con la familia Khan. Siempre era lo mismo lo que me sacaba de quicio: la forma en que los hombres trataban a las mujeres», p. 11. Otro ejemplo significativo lo tenemos en la vida y obra del académico y literato de la Universidad de Columbia de origen palestino y autor de la influyente obra titulada Orientalismo (1a ed. 1978) (editorial Libertarias, Madrid, 1990), Edward Said, quien, a partir de la guerra árabe-israelí de 1967, sufre una transformación radical, como comentan dos estudiosos de su vida y obra, Bill Ashcroft y Pal Ahluwalia: "Ya no podía vivir dos vidas, mantener dos identidades [...] La significación de esta transformación en la vida de Edward Said radica en el hecho de que, por primera vez, empezó a pensar en su propia identidad, a forjarse una identidad palestina a través de una articulación consciente del sentido de su origen cultural, reprimido desde su infancia y diversificado en su carrera profesional», en AshCROFT, B.; AHLuWALIA, P. (2000), Edward Said, la paradoja de la identidad, Barcelona: Bellaterra, p. 10. Lo significativo es que, en sentido contrario, "Es toda una ironía que sus obras hayan sido prohibidas en la propia Palestina [...] Yasir Arafat [...] no ha podido asimilar la identidad estadounidense de Said (un hecho que se puso claramente de manifiesto en la entrevista de Said con Tariq Alí en 1994)», p. 20. 
El llamamiento de Morin a conjugar la unidad del género humano a través de su identidad con la diversidad cultural sería un verdadero avance para contrarrestar diferentes acciones humanas llevadas a cabo en todas las épocas históricas en nombre de la singularidad de un pueblo, nación, etnia, etc., a partir de una definición etnocéntrica de las cualidades de su raza, etnia, nación o religión, que han desembocado, por ejemplo, tanto en la barbarie, como en el salvajismo (léase genocidios, etc.), como en movimientos nacionalistas de corte étnico, fundamentalismos religiosos, etc. ${ }^{7}$

Dejando a un lado la propuesta utópica de Morin, en el sentido de lo inalcanzable de encontrar la unidad del género humano en la diversidad, lo cierto es que tanto los sujetos como las colectividades construyen sus identidades a partir de la interpretación que en cada momento hacen ${ }^{8}$, según sus diferentes intereses ${ }^{9}$, del acervo cultural tanto material como inmaterial, los valores, los mitos, el territorio, la historia, etc., proyectando un marco de referencia de vida duradero y estable posiblemente en varias generaciones frente a los «otros».

Desde la misma perspectiva de la génesis identitaria, se encuentra el planteamiento de Castell, que defiende la idea de que quienes construyen las identidades colectivas y establecen su fundamentación teórica definen «su contenido simbólico y su sentido para quienes se identifican con ella o se colocan fuera de ella» ${ }^{10}$, y como las identidades se construyen siempre en contextos de relaciones de poder, propone una tipología sobre la génesis de la construcción de las identidades basada en el proceso natural que se da ante una estructura de poder: su legitimación para el mantenimiento del statu quo; la alternativa a través del conflicto y, por último, el cambio social.

A las primeras, las denomina «identidades legitimadoras», que son «introducidas por las instituciones dominantes de la sociedad para extender y racionalizar su dominación frente a los actores sociales [...]»"1 , como es, por ejemplo, para el caso de España, en la distribución territorial del poder, la identidad que confiere el Estado autonómico y su interiorización por parte de la gran

7. Como decíamos más arriba, la «identidad del yo», o el «yo sujeto» en la terminología morinniana, surge de la intersubjetividad con el otro y, por ello, "cada sujeto humano puede considerarse a la vez como sujeto y como objeto, e igualmente objetivar al otro al tiempo que lo reconoce como sujeto. Desgraciadamente, es capaz de dejar de ver la subjetividad de los otros y considerarlo sólo como objetos. A partir de ahí, se vuelve "inhumano" porque deja de ver su humanidad, o por el contrario, sólo puede amar u odiar ciegamente», en ibídem, p. 88.

8. Como bien afirma Eriksen, «las identidades son ambiguas, y esa ambigüedad está conectada con una historia negociable y un contenido cultural negociable», en ERIKSEN, T. H. (1993), Ethnicity and nationalism, Londres: Pluto Press, p. 73.

9. Guibernau analiza el proceso de generación de la identidad en el ámbito del nacionalismo y que puede ser extrapolable al resto de identidades colectivas: «En tanto que formas simbólicas, los fenómenos culturales poseen significado para quienes participan en ellos y el significado es algo que únicamente los "de dentro" comprenden y valoran», en GUIBERNAU, M. (1996), Los nacionalismos, Barcelona: Ariel, p. 89.

10. Castell, M. (1998), La era de la información. El poder de la identidad, vol. 2, Madrid: Alianza, p. 29.

11. Ibídem, p. 30. 
mayoría del pueblo español, frente a ciertas tendencias secesionistas, tanto pretéritas como actuales.

La segunda es la identidad de resistencia, «generada por aquellos actores que se encuentran en posiciones y condiciones devaluadas o estigmatizadas por la lógica de la dominación, por lo que construyen trincheras de resistencia basadas en principios diferentes a los que dicta la sociedad ${ }^{12}$. Así surgen los movimientos nacionalistas con objetivos de secesión, irredentismo o pannacionalismo, y también los fundamentalismos religiosos, entre otros.

La tercera, la identidad proyecto, hace referencia a los actores sociales ${ }^{13}$, que, «basándose en los materiales culturales de que disponen, construyen una nueva identidad que redefine su posición en la sociedad y, al hacerlo, buscan la transformación de toda la estructura social» ${ }^{14}$; son los casos de diferentes movimientos sociales, entre otros los feministas, ecologistas ecopacifistas, antiglobalización, etc.

Otra forma de entender la identidad es a través de la ciudadanía.

En el ámbito de los estados de corte occidental, la ciudadanía es una forma de identidad que puede interpretarse en dos contextos diferentes: como individuos libres e iguales en derechos ante la ley de esos estados o, como especifica Kymlicka, «miembros de determinados grupos [que] se incorporan a la comunidad política no sólo en calidad de individuos, sino también a través del grupo, y sus derechos dependen, en parte, de su propia pertenencia de grupo» ${ }^{15}$.

Ambas formas de entender la ciudadanía nos llevan bien a la identidad compartida basada en expectativas comunes e indiferenciadas para todos o a la desunión si está diferenciada en función del grupo. Por ejemplo, la situación que viven las sociedades occidentales actuales como consecuencia de los procesos de inmigración y la consecuente población multicultural y multirracial presenta un dilema: dadas por satisfactorias las funciones que cumple el Estado de bienestar en este tipo de sociedades, la de salvaguardar del equilibrio del sistema democrático dependerá del talante y las actitudes de los ciudadanos, así como de sus sentimientos de identidad y de cómo consideran otras formas identitarias diferentes, ya sean de género, clase, nacionales, étnicas o religiosas.

12. Ídem. Como apunta Rubert de Ventós, «Existe un sentido de identidad o pertenencia, individual y colectiva, tan básico como pueda serlo el impulso al alimento o la procreación. Una conciencia de sí como individuo que brota cuando halla una resistencia; una percepción de sí como grupo que se refleja narcisistamente en el espejo de un "nosotros" y se define dialécticamente — como el amo de Hegel— frente a los "otros" [...]", en ob. cit., p. 140.

13. En este caso, Castell especifica que los sujetos deben entenderse en el sentido atribuido por Touraine, como actores sociales colectivos donde los sujetos «alcanzan un sentido holístico en su experiencia», en ibídem, p. 32. Cfr. Touraine, A. (1995), «La formation du sujet», en Dubet, Wieviorka, M. (ed.), Penser le sujet, París: Fayard, p. 21-46.

14. Ibídem, p. 30.

15. KymlickA, W. (1996), Ciudadanía multicultural, Barcelona: Paidós, p. 240. 
No obstante, Kymlicka entiende que esta reivindicación de ciudadanía a través del grupo no tiene porqué desunir ni ser un peligro para el sistema. La mayoría de las reivindicaciones poliétnicas demuestran que los miembros de los grupos minoritarios desean participar en el conjunto de la sociedad. De hecho, las políticas multiculturalistas llevadas a cabo en muchos países occidentales, especialmente los Estados Unidos de Norteamérica, Canadá, Australia e Inglaterra, han conseguido acomodar a estos grupos étnicos y religiosos y no dejarlos marginados respecto del conjunto social.

En definitiva, el cómo, el por quién y el con qué, resultado de cada una de estas identidades, deben estar sujetos a un contexto social o a una circunstancia histórica.

Desde el punto de vista individual, la identidad podemos entenderla como reflexiva desde el momento que cada sujeto debe conformarla a partir de su propia autobiografía. Como dice Amin Maalouf, conocido novelista de origen libanés exiliado en Francia, «Igual que otros hacen examen de conciencia, yo a veces me veo haciendo lo que podríamos llamar "examen de identidad" ${ }^{16}$, valoración que le lleva a afirmar el carácter tanto multidimensinal como monodimensional de la misma, confiriendo en este último caso al sujeto una identidad única e intransferible ${ }^{17}$.

Además, a través de cada una de las pertenencias individuales, como por ejemplo la religión, los sujetos pueden estar unidos con otros muchos, pero a la vez, si tenemos en cuenta todas las pertenencias de cada individuo, forman la identidad propia del sujeto, inconfundible con otros.

Las identidades, a la vez que refuerzan la idea de semejanza entre los sujetos, también lo hacen en sentido contrario: cada uno es distinto a los demás, es único. Un español es diferente de un francés, pero también cada español es distinto de todos los demás y, dentro del contexto de España, un andaluz es diferente de un catalán, siendo los andaluces diferentes entre sí de la misma forma que lo son los catalanes.

El problema es que esta singularidad, la mayoría de la veces, es contextualizada en un mismo cajón estereotipado, por diferentes motivos, lo que provoca grandes injusticias, ya que, cuando generalizamos, atribuimos opiniones colectivas, crímenes, deportaciones a colectivos enteros, léase, «los servios masacran a los bosnios», «los vascos son secesionistas», que a veces terminan siendo creídas por los demás.

16. Maalouf, A. (2002), Identidades asesinas, Madrid: Alianza, p. 24. Entre los diferentes ejemplos que de su propia autobiografía señala que: «El hecho de ser cristiano [melquita, comunidad católica griega, según especifica el propio autor] y de tener por lengua materna el árabe, que es la lengua sagrada del islam, es una de las paradojas fundamentales que han forjado mi identidad», p. 24.

17. Así, dice Maalouf, "gracias a cada una de mis pertenencias, tomadas por separado, estoy unido por un cierto parentesco a muchos de mis semejantes; gracias a esos mismos criterios, pero tomados todos juntos, tengo mi identidad propia, que no se confunde con ninguna otra», en ibídem, p. 27. 
Muchas son las identidades que forjan el carácter de las personas y de las comunidades, ya sean pueblos o naciones, y las mismas están jerarquizadas, aunque no son inmutables, sino que cambian con el tiempo y modifican los comportamientos ${ }^{18}$.

Smith lo explica diciendo: «La historia de Edipo subraya claramente el problema de la identidad, ya que desvela cómo el yo está constituido por múltiples identidades y roles: familiares, territoriales, de clase, religiosos, étnicos y sexuales. También pone de manifiesto como todas estas identidades se basan en clasificaciones sociales que pueden ser modificadas o incluso abolidas» ${ }^{19}$.

Ninguna identidad tiene la facultad del primordialismo, ya sea la religión, la nación, la clase social, la pertenencia étnica, el género, la lengua, etc. Otra cosa es que cada una de ellas prime en un determinado país, según qué tiempo histórico o sus circunstancias.

Por otra parte, reducir la identidad de los sujetos a una sola pertenencia es cargar las tintas de la intolerancia, el sectarismo y el fanatismo, ya sea religioso, nacional o de clase, y ahí esta la historia para corroborarlo ${ }^{20}$.

La identidad nacional y territorial ha pretendido ser, para algunos partidos y movimientos nacionalistas, la única, de ahí la irracionalidad e intolerancia existente en sus acciones y manifestaciones de todo tipo, y España ha sido y es un ejemplo paradigmático.

Lo importante es entender la identidad desde un punto de vista relativista: todas nuestras trayectorias están influenciadas por los demás en mayor o menor grado, ya sea individual como colectivamente, a través del proceso histórico, por lo que la interiorización y posterior aceptación por parte de todos del «mestizaje identitario» sería la mejor solución a la cerrazón monolítica que mantienen muchas identidades colectivas.

Un ejemplo que fuerza la intransigencia identitaria la presenta Huntington en su defensa de la civilización occidental frente al resto de civilizaciones, en especial de la islámica, argumentando que el concepto de identidad está asociado

18. El caso de Edwars Said es un buen ejemplo, ya que éste se «identifica como una persona desmembrada "exiliada" de su patria. Pero, lejos de valorar el pasado a base de recrear una realidad cultural palestina esencial e incorruptible, insiste en que todas las culturas se hallan en cambio permanente, en que la cultura y la identidad son procesos. Ciertamente, su propia identidad cultural no se ha visto mermada, sino reforzada, por el hecho de haber optado por vivir en Occidente, en Estados Unidos, y, concretamente, en Nueva York. Primero es palestino y luego estadounidense», en AshCroft, B., Ahluwalia, P., ob. cit., p. 18.

19. SMITH, A. D., ob. cit., p. 3, aclara que de las categorías o roles que conforman el yo individual más importantes son: el género, la espacial o territorial, de clase, religiosa, étnicas y la nacional (ver p. 3-7).

20. Como acertadamente afirma Morin sobre el carácter dialógico de la historia, y más específicamente sobre las grandes religiones monoteístas que deberían estar fundamentadas en el amor, «la historia opone o une, sin discontinuidades, dos rostros contrarios: civilización y barbarie, construcciones y devastaciones, génesis y aniquilaciones», por este motivo, "Es cierto que hubo brotes sublimes de amor, aunque también desencadenamientos delirantes de amor que se consagran a los ídolos, las ideas, las idologías, las ideologías; las religiones del amor han sabido mejor que cualquier otro suscitar y alimentar el odio, en particular en las guerras de religión; el amor de la humanidad ha podido dejarse engañar por la inhumanidad», en ibídem, p. 229 y 231. 
a la teoría psicológica de la peculiariedad, propuesta que viene a decir que las personas se comprenden a partir de las características que nos distinguen de las demás, especialmente de las que comparten un mismo medio social habitual, por lo que, por ejemplo, una mujer de ideología nacionalista en companía de otras personas de otras ideologías pensará en sí misma como nacionalista, pero cuando se encuentre con un grupo de nacionalistas pensará más en sí misma como mujer. Desde esta perspectiva, en términos civilizacionales, la identidad de los individuos se concretará por lo que no son, $\mathrm{y}$ «a medida que el incremento de las comunicaciones, el comercio y los viajes multiplican las interacciones entre civilizaciones, la gente va concediendo cada vez más importancia a su identidad desde el punto de vista de la civilización» ${ }^{21}$.

Por otra parte, para la mayoría de los españoles, el contexto territorial y nacional es uno más entre otros muchos que conforman su personalidad individual y colectiva.

No obstante, es también una de las identidades a las que más importancia se ha dado y que ha conferido un mayor nivel de conflicto ${ }^{22}$.

Como anteriormente se ha indicado, cada sujeto tiene muchos referentes; pertenece normalmente a una nación o incluso a dos, profesa una religión, es miembro de algún grupo étnico, lingüístico, territorial o familiar, tiene una ocupación, está vinculado a alguna institución u organización y, además, puede sentirse perteneciente a su barrio, ciudad, clan o clase social, y todos estos dominios no tienen el mismo peso o importancia, o por lo menos simultáneamente, pero ninguno de ellos carece de valor.

No obstante, para el caso de España y su identidad territorial, existe alguna excepción. Entendemos que las otras tienen un menor peso, siempre relativo, al entender que son más generalistas y por lo tanto menos particularistas para convertirse en un valor diferencial a efectos autobiográficos, como son, por ejemplo: la religión (la mayoría se define como católica); la etnia o la raza (en España, a excepción de la gitana, no existe, excluyendo la de los inmigrantes); la lengua (el castellano es la oficial y, por lo tanto, la más común), aunque en este caso se establecen algunas excepciones en determinadas Comunidades Autónomas como Cataluña, País Vasco y Galicia, y en la actualidad, y en menor medida, la clase social.

No obstante, hay que señalar que aunque la identidad de los sujetos está formada por diferentes pertenencias, como hemos señalado, ésta es única y en caso de conflicto todas ellas se unifican en una defensa común. Además, en

21. Huntington, S. M. (1997), El choque de civilizaciones, Barcelona: Paidós, p. 78.

22. Como acertadamente apunta Smith, "Otros tipos de identidad colectiva (clase, género, raza o religión) pueden solaparse o mezclarse con la identidad nacional, pero rara vez logran minar su autoridad aunque puedan influir en el rumbo que tome», ibídem, p. 131. Por otra parte, Pérez Agote confiere al territorio, la historia y la lengua, ésta última en menor medida, la primacía identitaria, en «Modelo fenomenológico-genético para el análisis comparativo de la dimensión política de las identidades colectivas en el Estado de las autonomías", en BERAMENDI, J. G.; Maíz, R.; NúÑEZ, X. (1993), Nationalism in Europe. Past and present, vol. I, Santiago de Compostela: Universidad de Santiago de Compostela, p. 307-323. 
este caso puede establecerse cierta jerarquía, ya que la que haya sido objeto de burla, escarnio, vejación o sorna, en cualquier época histórica tomará la guía de acción inmediata, ya sea a través de la venganza, de la revancha, de la represalia o de la simple reivindicación. Cuando las acciones sobre identidades afectan a amplias colectividades, los que la comparten se movilizarán solidariamente en su afirmación utilizando diferentes estrategias, llevadas a cabo normalmente por minorías sociales, se denominen intelligentsia o élites de todo ámbito, que irán desde la negociación hasta la guerra abierta con los «otros» ${ }^{23}$.

En términos de jerarquía de prioridades, y en términos de poder, tanto en el momento de la aprobación de la Constitución, con el discutido Titulo VIII, y el modelo autonómico, como en la actualidad con el denominado "plan Ibarreche», o las reivindicaciones de reforma del Estatuto catalán, del andaluz, entre otros, la identificación territorial ha adquirido una cierta trascendencia, puesto que el armazón de la convivencia está en juego, lo que justifica su análisis.

El caso del País Vasco, y su persistente nacionalismo étnico, secesionista y segregacionista, de otras identidades no nacionalistas por parte de determinados colectivos y partidos políticos abertzale y no, es el paradigma de un programa rupturista con un modelo de Estado, el autonómico, que ofrece las mismas garantías y alternativas de autogobierno que el federal ${ }^{24}$, en el máximo de descentralización y autonomía, además de posibilitar un marco cívico y político de convivencia.

En términos concretos, la identidad nacional que mayor peso tiene en el mundo occidental, y por lo tanto la que predomina en España, está configurada, según $S_{m i t h}{ }^{25}$, por un territorio histórico, una comunidad político-legal,

23. Maalouf cree que esa tendencia, arraigada en la mayoría de los pueblos, es porque tienen una concepción tribal de la identidad. Como acertadamente apunta, "Hay un Mr. Hyde en cada uno de nosotros; lo importante es impedir que se den las condiciones que ese monstruo necesita para salir a la superficie», y expone su vivencia como ejemplo: "Tuve la suerte de no pasar por pruebas muy duras, de salir enseguida de la hoguera con los míos indemnes, tuve la suerte de mantener limpias las manos y clara la conciencia. Y digo "suerte", sí, porque las cosas habrían podido ser distintas si, cuando comenzó la guerra del Líbano, yo hubiera tenido dieciséis años en lugar de veintiséis, si hubiera perdido a un ser querido, si hubiera pertenecido a otro ámbito social, a otra comunidad...", en MAALOUF, A.; ob. cit., p. 35-37.

24. Aja dice al respecto: «El poder político de las Comunidades Autónomas puede compararse perfectamente con el que poseen los estados miembros de la federación, como por ejemplo los Länder alemanes o austríacos, y, desde luego, es muy superior al que tienen las regiones italianas», en AJA, E. (2003), El estado autonómico: Federalismo y hechos diferenciales, Madrid: Alianza, p. 14. No incluimos el modelo propuesto por el denominado «Plan Ibarreche» de Comunidad Libre Asociada de Euskadi, por entender que se trata de una propuesta rupturista con el modelo vigente, ya que no pretende una más o menos amplia modificación del Estatuto de Autonomía, sino que se trata de un verdadero estatuto constituyente.

25. Ibídem, p. 10. Este tipo de identidad nacional debe diferenciarse de la identidad nacional étnica, desarrollado principalmente en Europa Oriental y Asia. No obstante, la utilización que hagan los nacionalistas de la nación abarcará tanto elementos cívicos como étnicos. Como puntualiza Smith: «En todos los nacionalismos hay, efectivamente, elementos cívicos y étnicos en diversos grados y formas: a veces predominan los elementos cívicos y territoriales, y en otros casos cobran mayor importancia los componentes étnicos y vernáculos», p. 11. 
la igualdad político-legal de sus integrantes y una ideología y una cultura cívicas colectivas.

\section{Metodología e hipótesis}

Partimos de la idea de que en España el sentimiento de identidad territorial detenta un cierto primordialismo al tener el resto, bien una condición generalista o bien inexistente.

Este hecho nos posibilita avanzar la hipótesis sobre el alto grado de relativismo identitario existente entorno a la estructura de la distribución territorial del poder en España.

Desde esta perspectiva, entendemos que en España existe un mestizaje identitario que explica suficientemente el arraigo de la mayoría de los españoles a identificarse tanto como españoles como de sus respectivas Comunidades Autónomas.

Entendemos por mestizaje identitario ${ }^{26}$ la normal interiorización y asunción del modelo autonómico como referente de convivencia en el ámbito de la distribución territorial del poder en España, y en esta línea estamos de acuerdo con la afirmación de Solé-Tura de que: «El modelo del Estado de la autonomías se basa en la negociación y en la cooperación, pero el nacionalismo sigue poniendo por delante el conflicto» ${ }^{27}$.

Analizaremos dos formas de identificación con el Estado de las autonomías: el primero a través del sentimiento de pertenencia a dos niveles territoriales que generan una conciencia de apego, relación y lazo, como son España y la Comunidad Autónoma de referencia, y que puede precisarse como una cercanía de vinculación plena con la nación existente, en un caso, proyectada en otros, centro de todas las aspiraciones comunes de particularismo cultural, autonomía política y desarrollo económico; el segundo a partir del apoyo o no de los ciudadanos a sus instituciones y a sus formas de gobernar.

Para la medición de la primera forma de sentimiento de identificación, utilizaremos la fórmula ampliamente utilizada y validada científicamente en diferentes investigaciones (ver la nota 30), donde se le ofrece al entrevistado una sola dimensión en la que autoubicarse, dimensión que presenta dos extremos: sentirse únicamente español, por un lado, o únicamente de la Comunidad Autónoma, por otro. Las posiciones intermedias consisten en significarse ambas cosas a la vez.

26. El mestizaje identitario puede conceptualizarse como una híbrida posición o interpretación extrema de entender España: bien como centralista bien como nacionalista, ambas con pretensiones excluyentes. En términos más gráficos, debe entenderse siguiendo la lógica de la frase pronunciada por el ex presidente del gobierno Felipe González y que el diario El País encuadró en el siguiente titular: «Felipe González arremete contra los políticos que dictan una forma única de sentir la nacionalidad: "Cada uno se siente andaluz como quiere" y "Nadie puede decirme cómo tengo que ser catalán, gallego o español”", en El País (Andalucía), viernes, 24 de octubre de 2003, p. 6.

27. Solé Tura, J. (1985), Nacionalidades y nacionalismos en España: Autonomías, federalismo, autodeterminación, Madrid: Alianza, p. 64. 
Como veremos más adelante, serán estas posiciones intermedias las que determinarán claramente la interiorización del modelo autonómico por parte de la mayoría de los españoles, es decir, se podrá afirmar que en España existe una identificación dual o nacionalidad compartida o, más específicamente, que la mayoría se sienten tanto españoles como de sus respectivas comunidades autónomas, tanto de nacimiento como de libre elección.

Ademas, reforzaremos la medición con dos escalas: la primera, de identificación con España, la Comunidad Autónoma y la Unión Europea; la segunda, de orgullo de pertenencia a España y a la Comunidad Autónoma.

Por último, mediremos el apoyo de los ciudadanos a sus instituciones o formas de gobernar a partir del nivel de confianza otorgado al gobierno de España y el de la Comunidad Autónoma.

Desde esta perspectiva, creemos que tiene razón Aja cuando afirma que: «los ciudadanos necesitan entender la lógica que guía a las instituciones y éstas, a su vez, requieren la identificación de los ciudadanos con su forma de gobernar» ${ }^{28}$, praxis y sentimientos que no necesariamente finaliza cada cuatro años en las distintas elecciones, sino en la posición identificativa que tienen los ciudadanos con el sistema autonómico.

\section{Análisis de los resultados}

\section{La identificación dual o nacionalidad compartida}

Respecto al sentimiento vinculativo con el territorio, como puede apreciarse en la tabla 1, y teniendo en cuenta la puntualización metodológica señalada en la introducción (ver nota 2), algo más de la mitad de la población española afirma tener una identificación dual o compartida ${ }^{29}$, lo que confirma nuestra hipótesis del relativismo identitario en España, por lo que se acepta la idea de ese mestizaje identitario que anteriormente señalábamos y que refuerza el modelo de la distribución territorial del poder plasmado en lo que se ha venido en denominar el «Estado autonómico» 30 .

28. AJA, E. (2003), El estado autonómico: Federalismo y hechos diferenciales, Madrid: Alianza, p. 50.

29. Lógicamente, se dan excepciones a esta generalización cuando introducimos otros tipos de variables y nos situamos en una determinada Comunidad. Por ejemplo, en Cataluña la identificación dual es menor que la que se posiciona como «más catalán que español» entre el colectivo de individuos nacidos en Cataluña cuyos padres son nativos de esa comunidad, en Virós, M. R.; Canals, R. M.; PALlarés, F. (1991), «Influència d'alguns factors sòciodemogràfics i polítics. Perfil dels electorats», en L'electorat català a les eleccions autonòmiques de 1988: opinions, actituds i comportaments, Equipo de Sociología Electoral. Barcelona: Fundació Jaume Bofill. Cfr. KEATING, M. (1996), Naciones contra el Estado: El nacionalismo de Cataluña, Québec y Escocia, Barcelona: Ariel, p. 161.

30. Muchas han sido las investigaciones realizadas en España que corroboran la tendencia, bien a situarse entorno a la mitad de la población si tenemos sólo en cuenta la categoría "tan andaluz... como español»; y casi las tres cuartas partes de la población si le sumamos las categorías, "más andaluz... que español» y «más español que andaluz....». Entre las más significativas: los primeros estudios sobre la conciencia nacionalista en España se encuentra el dirigido por José JiméNEZ BlanCO y otros (1977), La conciencia regional en España, 
Si contabilizamos el porcentaje de españoles que se adhieren al ámbito español y autonómico, éste alcanza en el periodo analizado casi las tres cuartas partes.

Más claramente, si forzamos la realidad y recodificamos las cinco categorías iniciales en tres: nacionalistas, identificación dual y españolistas, observamos que más de la mitad de la población se sigue vinculando tanto con España como con su Comunidad Autónoma y que los otros dos cuartos restantes, bien se definen como nacionalistas bien como españolistas.

En resumen, podemos afirmar que para la mayoría de los españoles la identificación no significa exclusión.

Esta primacía de doble tendencia podría explicarse, como bien apunta Moreno, por el hecho de que «la doble nacionalidad manifestada en una lealtad compartida a las instituciones estatales y subestatales y ligada al modo de identidad dual de los españoles, refleja el solapamiento en muchos casos de las afinidades territoriales entre lo general y lo particular. Se produce así una congruencia espontánea y simultánea entre lo español y lo andaluz/catalán/vasco etc.» $^{31}$, pero también se explica como la más firme convicción, por parte de la mayoría de los españoles, de la interiorización del modelo autonómico como referente de entendimiento de las políticas de la distribución territorial del poder.

Madrid, CIS, auténtico referente metodológico en las investigaciones posteriores sobre las identidades colectivas y, más concretamente, sobre la conciencia nacionalista y autonomista. Además, ver CAMPO, S. DEL; NAVARro, M.; TEZANOS, F. (1977), La cuestión regional española, Madrid: Edicusa; GARCÍA FERRANDO, M. (1982), Regionalismo y autonomía en España (1976-1979), Madrid: CIS; García FERrando, M.; López Aranguren, E.; BELTRÁN, M. (1994), La conciencia nacional y regional en la España de las autonomías, Madrid, CIS; LÓPEZ ARANGUREN, E. (1993), La conciencia regional en el proceso autonómico español, Madrid: CIS; López Aranguren, E.; García Ferrando, M. (1991), «Nacionalismo y regionalismo en la España de las Autonomías», en Vidal BENEYTO, J. (comp.), España a debate. La sociedad, Madrid: Tecnos; Herranz, G. (1996), «Estructura social e identificación nacionalista en la España de los noventa», Revista Española de Investigaciones Sociológicas, núm. 76, p. 9-35, p. 17-19. Más cercano en el tiempo, Moreno realiza el mismo análisis partiendo de las mismas categorías y fuentes, aunque su periodo abarca de 1990 a 1995 y llega a conclusiones parecidas: "De acuerdo con los datos agregados del conjunto español en el periodo 1990-1995 [...], la base de esta identidad dual, es decir, el porcentaje de ciudadanos españoles que se situarían con diferentes grados de adhesión en las esferas española y autonómica es superior a los dos tercios [aquí incluye Moreno las categorías "más andaluz, catalán... que español” y la de "más español que andaluz, catalán...”. El porcentaje de ciudadanos que se autoidentificarían exclusivamente es, en cualquier caso, menor de un tercio. Una quinta parte del conjunto ciudadano se identifica únicamente como español, mientras que casi una décima parte lo hace exclusivamente con su comunidad autónoma», en MORENO, L. (1997), La federalización de España, Madrid: Siglo XXI, p. 125 y 136.

31. MorEnO, L., ob. cit., p. 124. En otro sentido, no estamos de acuerdo con Moreno en su valoración final sobre la identificación dual, al interpretar que la misma puede ser un argumento poderoso para la consolidación, «de un tipo de federalismo basado en las lealtades políticas compartidas de sus ciudadanos», p. 140. Creemos que la nacionalidad compartida es característica del modelo autonómico y es en el mismo donde cobra sentido. 


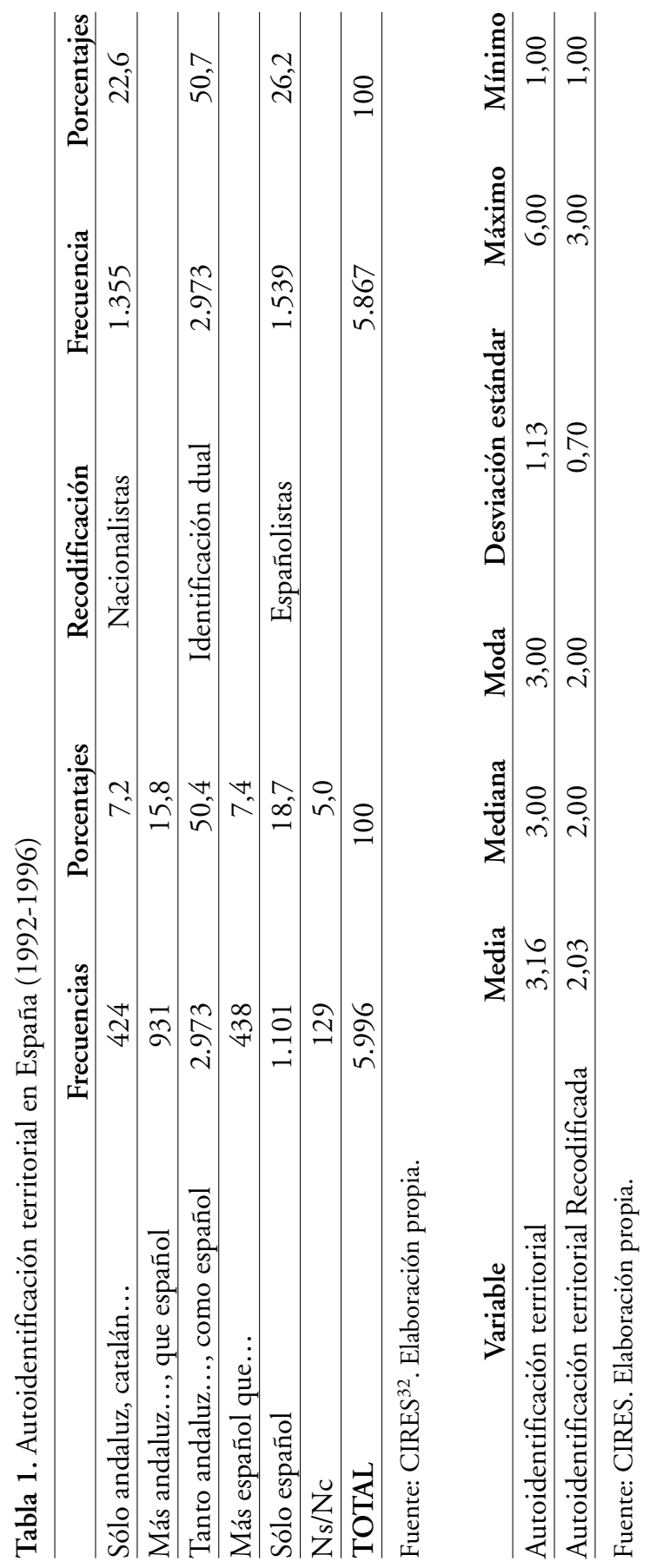


No obstante, esta descripción de la realidad debe ser matizada, ya que, en efecto, aunque los sentimientos de pertenencia por sí solos no aclaran la complejidad de la realidad territorial en España, sí supone un eslabón más a añadir junto a otros niveles de análisis: la identificación y el orgullo de pertenecer a España, a la Comunidad Autónoma o a la Unión Europea.

Uno de los límites lo señala, por ejemplo, Aja, quien entiende que establecer disimilitudes en los hechos diferenciales de las distintas Comunidades Autónomas ${ }^{33}$ alejándose de los criterios jurídicos y arrogándose a factores políticos o ideológicos que posibiliten afirmar que algunas de estas comunidades son diferentes porque la población tiene un sentimiento de ser una nación o porque tienen partidos nacionalistas, es un error. En términos concretos, Aja critica la consideración de los hechos diferenciales a través de la medición unilateral de los sentimientos de identificación territorial.

Además, establece una objeción técnica a la medición de estos sentimientos, ya que no concretan posiciones institucionales posibles. Según él, un mismo sentimiento puede dar respuesta a diferentes opciones políticas, "(por ejemplo, sentirse más vasco que español) puede dar lugar a opciones políticas tan diferentes como la autonomía y la independencia, y a identificaciones con partidos políticos diversos. Se puede ser autonomista (defensor de la autonomía y de sus caracteres, incluidos los hechos diferenciales) y no ser nacionalista, y se puede ser nacionalista partidario del sistema autonómico o contrario a él y defensor de la independencia» ${ }^{34}$.

En efecto, aunque pueda dar lugar a opciones políticas diferentes, no quita que se acepte el modelo autonómico como eje vertebrador del ordenamiento político territorial, que es, en definitiva, lo significativo.

Además, a través de esta escala autoidentificativa, aquellos sujetos que se sienten nacionalistas, partidarios o no de la autonomía o de la independencia, tienen su propia ubicación que para el periodo analizado supone el 7,2\% o, en todo caso, en el supuesto más favorable, no alcanzan la cuarta parte de la población española.

32. El cuadro refleja los resultados de una muestra agregada de 6.000 encuestas de los años 1992 a 1996. La muestra de cada una de esas encuestas realizadas por CIRES a lo largo de esos años consiste en 1.200 personas de más de 18 años representativas de la población española con un error muestral del 2,89\% para el caso más desfavorable de $p=0,5$ y con un margen de confianza del $95,5 \%$.

33. El análisis de Aja se fundamenta en la comparación entre el modelo autonómico y el federal. Partiendo del hecho de que el federalismo moderno actual tiene unas connotaciones cooperativas claras además de estructurarse en base a la igualdad constitucional, los hechos diferenciales en el modelo autonómico aún cuando desde un punto de vista jurídico vienen claramente plasmados en la Constitución y constituyen un acervo más de las características distintivas de los diversos pueblos de España, algunos sectores nacionalistas lo utilizan para incidir en la diferencia ideológica e identificativa como nación y así distanciarse de otras Comunidades Autónomas.

34. AJA, E., ob. cit., p. 200-201. 


\section{Orgullo e identificación con España, la Comunidad Autónoma y Europa}

Posteriormente, se introdujo una matriz de correlaciones de una serie de variables y sus correspondientes recodificaciones relacionadas, tanto con los niveles de identificación ${ }^{35}$ con España, la Comunidad Autónoma y Europa, incluido el orgullo ${ }^{36}$ de pertenecer a las mismas, así como los grados de confianza que generan sus respectivos gobiernos.

Tabla 2. Correlaciones de Pearson (1992-1996)

\begin{tabular}{|c|c|c|c|c|c|c|c|c|}
\hline & C68 & C70 & C72 & D12 & D14 & D17 & D19 & D21 \\
\hline C68 & & 0,6526 & & & & & & \\
\hline $\mathrm{C} 70$ & & & 0,6142 & & & & & \\
\hline \multicolumn{9}{|l|}{ C72 } \\
\hline$\underline{\mathrm{D} 12}$ & & & & & 0,6331 & & 0,7356 & \\
\hline D14 & & & & 0,6331 & & 0,6663 & & \\
\hline \multicolumn{9}{|l|}{ D17 } \\
\hline D19 & & & & 0,7356 & & 0,5479 & & 0,4303 \\
\hline D21 & & & & & & & 0,4304 & \\
\hline
\end{tabular}

\section{D14X D19X D17XX D19XX}

D14X 0,4403

D19X

\begin{tabular}{lll}
\hline D17XX & 0,5595 \\
\hline D19XX & 0,5595 & \\
\hline
\end{tabular}

Fuente: CIRES. Elaboración propia ${ }^{37}$.

35. Entendemos la «identificación» en el sentido dado por Durkheim en su obra Las formas elementales de la vida religiosa, Buenos Aires: Schapire, 1968, como un sentimiento de lealtad y de pertenencia al grupo, que se especifica tanto en la aceptación axiológica, normativa y valorativa del mismo como simbólica a través de sus múltiples manifestaciones.

36. En este trabajo, entendemos por «orgullo» un sentimiento de satisfacción por algo propio y personal que se considera digno de mérito, ya sea éste el hecho de pertenecer a una determinada nación, familia etc., profesar determinada religión o pertenecer a cualquier otra institución, organización, etc.

37. Se introdujeron una amplia gama de variables, incluidas algunas sociodemográficas, así como de la autoidentificación territorial. Pusimos de tope mínimo por encima del 0,40 para garantizar una relación de asociación sustancial entre las series. Además, algunas de ellas se recodificaron, aunque la mayoría mantuvieron la estructura de la escala original. Las variables fueron las siguientes: C68, «Confianza en el Gobierno de España»; C70, "Confianza en el Gobierno de la comunidad autónoma»; C72, «Confianza en el Gobierno de la Unión Europea»; D12, "Orgullo hacia España como país»; D14, «Orgullo hacia la comunidad autónoma»; D19, «Grado de identificación con España»; D17, «Grado de identificación con la comunidad autónoma»; D21, «Grado de identificación con la Unión Europea»; D14x, «Orgullo hacia la comunidad autónoma (recodificada)»; D19x y D19xx, «Grado de identificación con España (recodificada)»; D17xx, «Grado de identificación con la comunidad autónoma (recodificada)». 


\section{Desviación}

Variables $\quad \mathrm{N}$ Media estándar Mínimo Máximo

\begin{tabular}{|c|c|c|c|c|c|c|}
\hline $\mathrm{C} 68$ & $\begin{array}{l}\text { Confianza en el Gobierno } \\
\text { de España }\end{array}$ & 2.320 & 4,48 & 2,71 & 0,00 & 10,00 \\
\hline $\mathrm{C} 70$ & $\begin{array}{l}\text { Confianza en el Gobierno } \\
\text { de la CA }\end{array}$ & 2.293 & 5,09 & 2,51 & 0,00 & 10,00 \\
\hline$\underline{\mathrm{D} 12}$ & Orgullo España & 5.954 & 8,25 & 2,37 & 0,00 & 10,00 \\
\hline $\mathrm{D} 14$ & Orgullo hacia la CA & 5.941 & 8,38 & 2,07 & 0,00 & 10,00 \\
\hline D19 & $\begin{array}{l}\text { Grado de identificación } \\
\text { con España }\end{array}$ & 4.760 & 8,19 & 2,10 & 0,00 & 10,00 \\
\hline D17 & $\begin{array}{l}\text { Grado de identificación } \\
\text { con la CA }\end{array}$ & 4.750 & 8,17 & 2,12 & 0,00 & 10,00 \\
\hline $\mathrm{D} 21$ & $\begin{array}{l}\text { Grado de identificación } \\
\text { con la UE }\end{array}$ & 4.652 & 6,46 & 2,51 & 0,00 & 10,00 \\
\hline $\mathrm{D} 14 \mathrm{x}$ & $\begin{array}{l}\text { Orgullo hacia la CA } \\
\text { (recodificada) }\end{array}$ & 5.941 & 3,45 & 0,74 & 1,00 & 4,00 \\
\hline $\mathrm{D} 19 \mathrm{x}$ & $\begin{array}{l}\text { Grado de identificación } \\
\text { con España (recodificado) }\end{array}$ & 4.760 & 3,38 & 0,75 & 1,00 & 4,00 \\
\hline $\mathrm{D} 19 \mathrm{xx}$ & $\begin{array}{l}\text { Grado de identificación } \\
\text { con España (recodificado) }\end{array}$ & 4.760 & 4,93 & 1,15 & 1,00 & 6,00 \\
\hline D17xx & $\begin{array}{l}\text { Grado de identificación } \\
\text { con la CA (recodificado) }\end{array}$ & 4.750 & 4,92 & 1,16 & 1,00 & 6,00 \\
\hline
\end{tabular}

Fuente: CIRES. Elaboración propia.

Como puede apreciarse, hay una relación sustancial de asociación entre las distintas variables, tanto las relacionadas con el orgullo hacia España como país, y la Comunidad Autónoma, como en los niveles de identificación con España y las Comunidades Autónomas.

Como puede apreciarse en el la tabla 3, los que no se sienten orgullosos de ser españoles y de su Comunidad Autónoma representan el 26,3\%.

Aquéllos que no experimentan satisfacción por ser españoles y en cambio dicen estar muy orgullosos de su comunidad, suponen el 31,6\% de la población.

A partir del nivel 3 de la escala ${ }^{38}$, cuanto más apego siente uno por España, más también por su Comunidad Autónoma, hecho que viene a completar la tendencia de la identificación dual. Los que se sienten muy orgullosos de España y su autonomía suponen el 87,6\% de la población.

38. Los diferentes niveles de la escala fueron recodificados con las siguientes categorías: D14x, «Orgullo hacia la comunidad autónoma (recodificada), y D19x «Identificación con España: 1. nada, 2. algo, 3. bastante, 4. totalmente», y D19xx, "Grado de identificación con España (recodificadas)" y D17xx, "Grado de identificación con la comunidad autónoma (recodificada): 1. nada, 2. poco, 3.algo, 4.bastante, 5. mucho, 6. totalmente». 


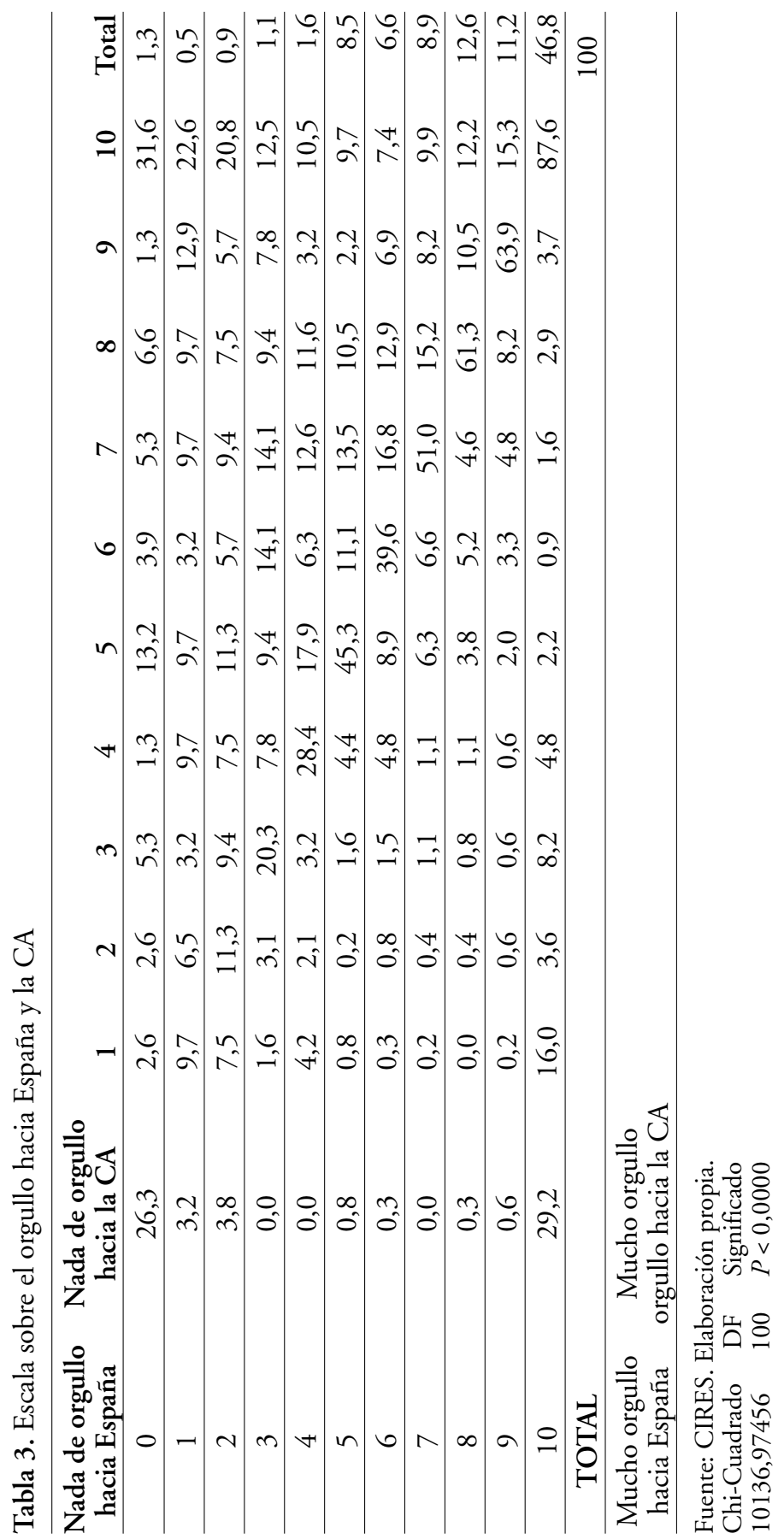


No obstante, debe consignarse que los sentimientos de exclusiva pertenencia a España son significativos $(29,2 \%)$.

En las tablas 4 y 5, observamos una clara coincidencia entre las correlaciones entre el orgullo de ser Español o de la Comunidad Autónoma respectiva y el grado de identificación con España y la Comunidad, que, en ambos casos, en los niveles máximos, están entorno a las tres cuartas partes de la población.

Debe destacarse el hecho que, tanto el máximo eslabón de pertenencia a España como a la Comunidad Autónoma esté complementado por el mínimo, por debajo del 1\%, de aquéllos que no han adquirido ningún tipo de identificación con ambas.

Además, ambos sentimientos también experimentan una fuerte asociación en los niveles extremos, ya que la nula satisfacción con España sólo alcanza un $1,8 \%$ del máximo de identificación con la misma, tendencia que ocupa el 2,4\% para el caso de la autonomía.

Por otra parte, los nulos sentimientos hacia su Comunidad se distribuyen por igual en su identificación con España, siendo la máxima diferencia de 7,8 puntos porcentuales entre los que se sienten españoles algo o bastante (niveles 2 y 3 de la escala; ver la tabla 6).

A medida que se amplían los estratos de satisfacción por pertenecer a la Comunidad Autónoma, se incrementan los sentimientos hacia España, especialmente en los niveles más altos, que llegan a alcanzar las tres cuartas partes de la población, tendencia que refuerza, desde una perspectiva valorativa, la nacionalidad compartida.

Respecto al grado de identificación con España y la Comunidad Autónoma, la tendencia es parecida a las anteriores: los que no se identifican nada ni con España ni con su Comunidad suponen algo más de un tercio, como puede observarse en la tabla 7, pero, a medida que avanzamos en los diferentes estratos (sobre todo a partir del nivel tres), algo mayores grados de identificación hay entre ambas realidades territoriales, de manera que llegan al 81\% los sentimientos compartidos con ambas.

Conviene señalar también que las tendencias más extremas de nulo sentimiento hacia España y máximo hacia la autonomía alcanzan el 44,6\%.

Además, aquéllos que pueden considerarse universalistas puros sin ninguna vinculación con España suponen un escaso 7,8\%.

En sentido contrario, los más antieuropeístas con fuertes vínculos con España representan el 3,8\%.

En cambio, si valoramos la posición de los españoles respecto de España y la Unión Europea, la tendencia cambia, como puede observarse en la tabla 8: a medida que avanzamos en la jerarquía a mayores niveles de cercanía con España, la relación con la Unión Europea se sitúa en el grado máximo en el punto quinto de la escala (algo) con un 54,5\%, y disminuye a algo más de un tercio en aquéllos que señalan una total identificación entre ambos ámbitos territoriales. 


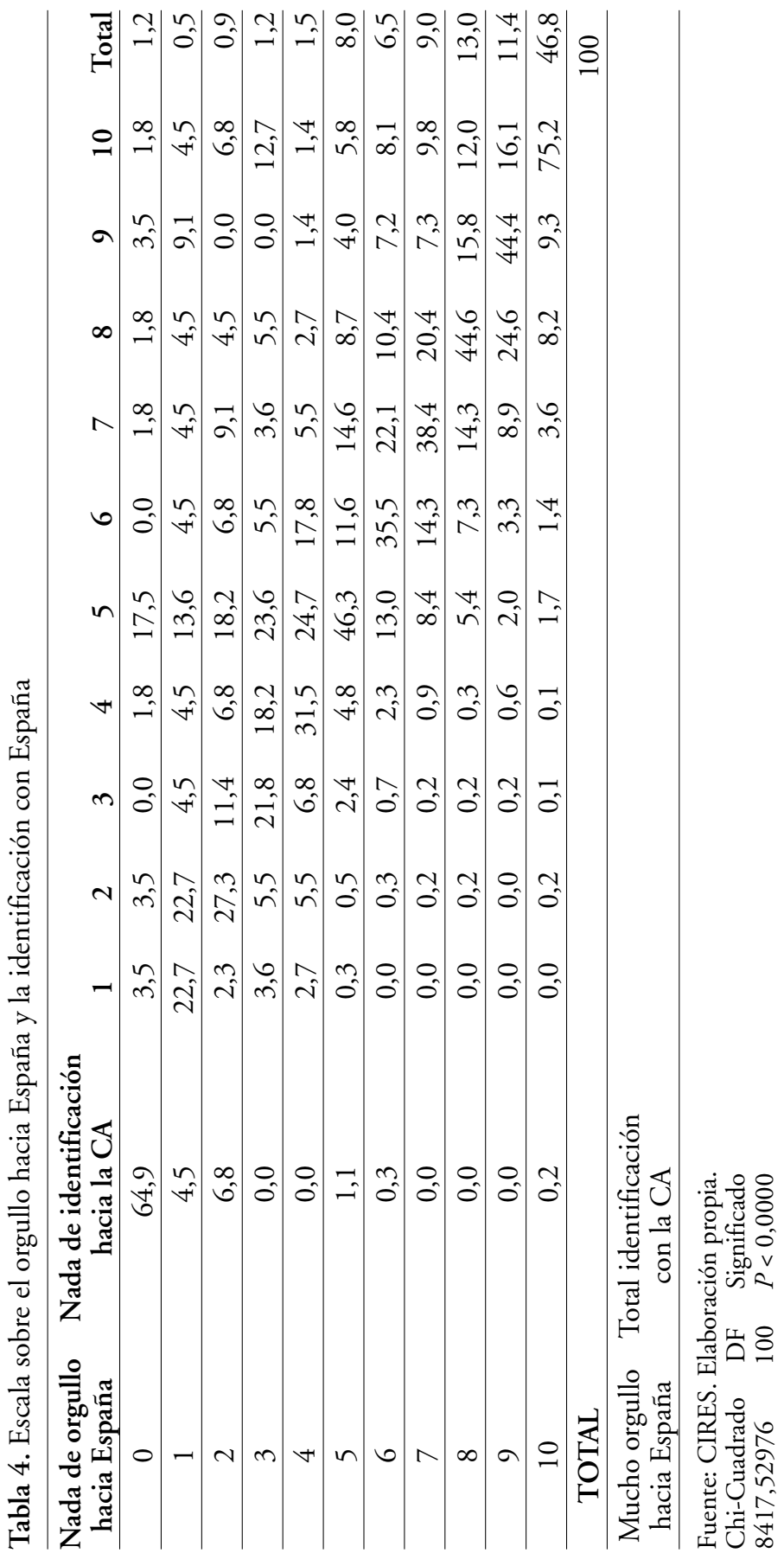




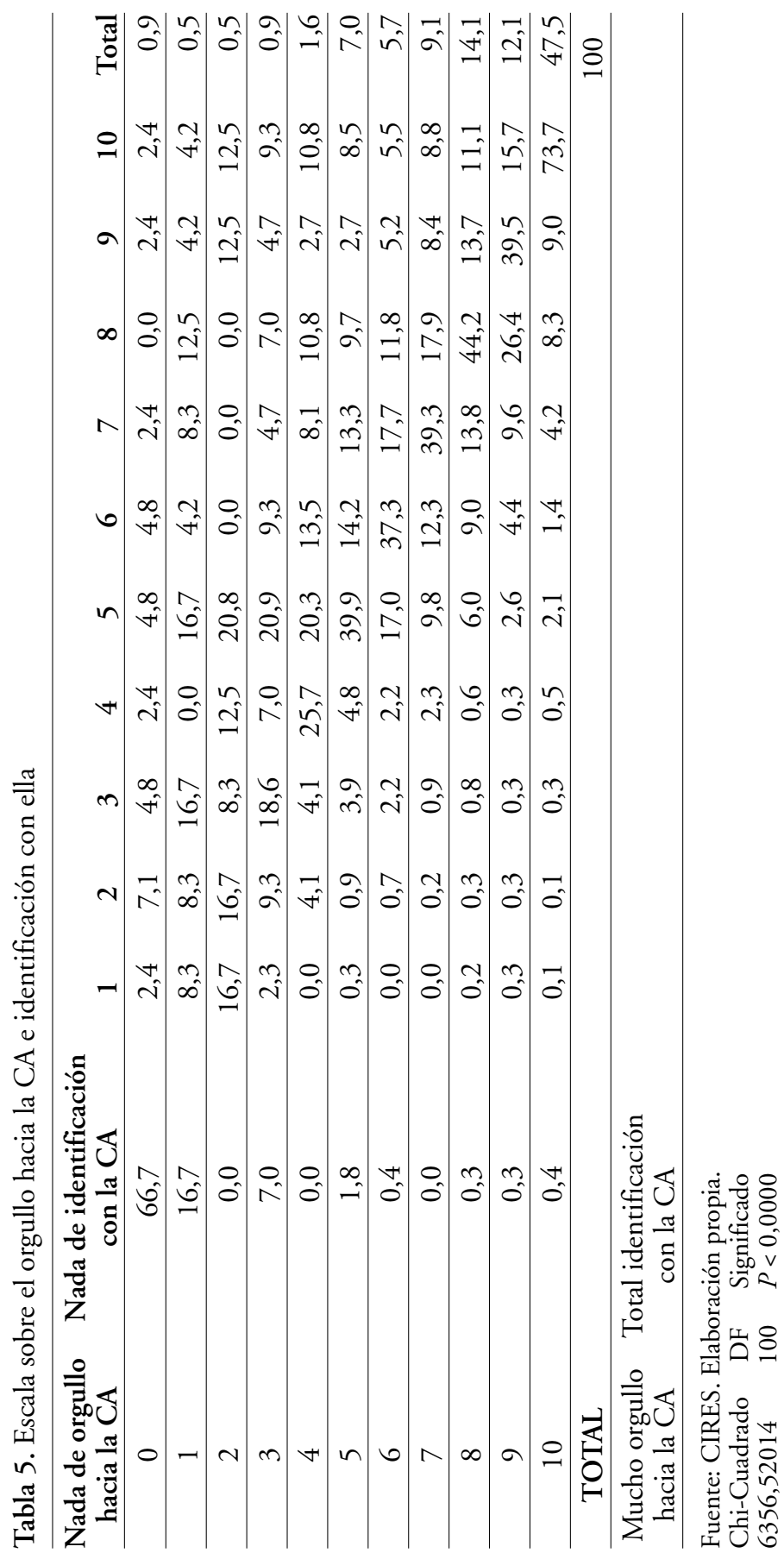


Tabla 6. Escala sobre el orgullo hacia la CA e identificación con España

\begin{tabular}{ccccccc}
\hline $\begin{array}{c}\text { Nada de orgullo } \\
\text { hacia la CA }\end{array}$ & $\begin{array}{c}\text { Nada de identificación } \\
\text { con España }\end{array}$ & $\mathbf{1}$ & $\mathbf{2}$ & $\mathbf{3}$ & $\mathbf{4}$ & Total \\
\hline 1 & & 26,7 & 21,1 & 28,9 & 23,3 & 100 \\
\hline 2 & 4,7 & 33,9 & 36,3 & 25,2 & 100 \\
\hline 3 & 0,7 & 14,3 & 61,2 & 23,8 & 100 \\
\hline 4 & 1,6 & 4,9 & 19,9 & 73,7 & 100 \\
\hline $\begin{array}{c}\text { Mucho orgullo } \\
\text { hacia la CA }\end{array}$ & $\begin{array}{c}\text { Total identificación } \\
\text { con España }\end{array}$ & & & & & \\
\hline
\end{tabular}

Fuente: CIRES. Elaboración propia.

Chi-Cuadrado DF Significado

$1620,50598 \quad 9 \quad P<0,0000$

Tabla 7. Escala sobre la identificación con España y con la CA

\begin{tabular}{ccccccccc}
\hline $\begin{array}{c}\text { Nada } \\
\text { de identificación } \\
\text { con España }\end{array}$ & $\begin{array}{c}\text { Nada } \\
\text { de identificación } \\
\text { con la CA }\end{array}$ & $\mathbf{1}$ & $\mathbf{2}$ & $\mathbf{3}$ & $\mathbf{4}$ & $\mathbf{5}$ & $\mathbf{6}$ & Total \\
\hline 1 & & 35,4 & 3,1 & 6,2 & 3,1 & 7,7 & 44,6 & 100 \\
\hline 2 & 6,6 & 25,0 & 15,8 & 10,5 & 15,8 & 26,3 & 100 \\
\hline 3 & 2,4 & 4,1 & 45,4 & 17,3 & 15,4 & 15,4 & 100 \\
\hline 4 & 1,0 & 1,7 & 11,2 & 59,1 & 18,7 & 8,3 & 100 \\
\hline 5 & 0,6 & 1,2 & 4,1 & 13,4 & 69,4 & 11,3 & 100 \\
\hline 6 & 0,9 & 0,9 & 3,2 & 4,0 & 9,3 & 81,8 & 100 \\
\hline
\end{tabular}

Total identificación Total identificación

con España con la CA

Fuente: CIRES. Elaboración propia.

Chi-Cuadrado DF Significado

$5079,00520 \quad 25 \quad P<0,0000$

Nivel de confianza en el gobierno de España y en la Comunidad Autónoma

Más institucionalmente, pretendíamos saber el grado de confianza de los españoles respecto del gobierno de España y también del de la comunidad autónoma, siendo conscientes, como antes dijimos, de que los ciudadanos necesitan entender y conocer como funcionan las instituciones y éstas, a su vez, requieren la interiorización y aceptación de los ciudadanos de su forma de gobernar. 


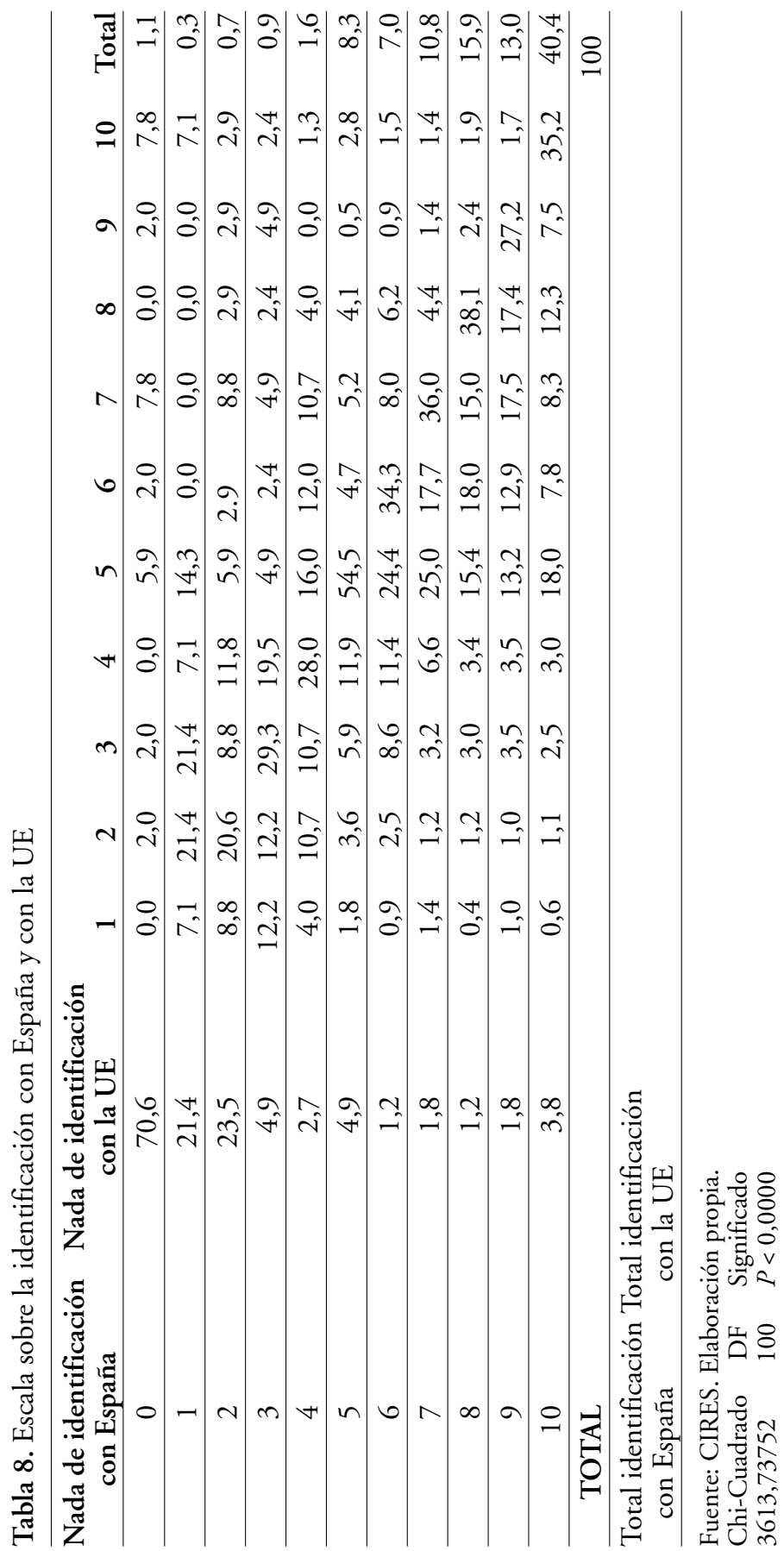


Como puede verse en la tabla 9 sobre los grados de confianza de ambos gobiernos, aquéllos que expresan ninguna confianza en ambos alcanzan el $46,2 \%$.

En sentido contrario, los que manifiestan nula confianza en el Gobierno de España y una confianza total en el de la comunidad autónoma respectiva, sólo representan el 2,5\% y, en sentido contrario, los que le dan plena confianza al Gobierno español y ninguna al de la comunidad autónoma no llega al 1\%.

Lo importante es que a medida que avanzamos en el nivel de credibilidad en el Gobierno de España, también lo hacemos en el de la comunidad autónoma en los estratos máximos, disminuye en las categorías inmediatamente inferiores (mucho y bastante) y se consolida en el nivel medio (alguna confianza). Ésta última representa el $55,4 \%{ }^{39}$.

\section{Conclusiones}

El nacionalismo en España es un referente obligado desde el momento en que, desde finales del siglo XIX hasta la actualidad, se convirtiera en el primer foco de conflictos y desestabilización de la convivencia.

La Constitución de 1978, al crear el modelo autonómico, ponía las bases para institucionalizar las posturas extremas sobre cómo debía interpretarse la distribución territorial del poder.

A las bases jurídicas, le siguieron otras de naturaleza más axiológica que han establecido nuevas formas de interpretar la vinculación de los españoles con el nuevo e innovador sistema.

Los datos refuerzan la hipótesis de partida de que en España predomina un relativismo en el ámbito territorial que se traduce en una especie de mestizaje identitario que explica suficientemente por qué más de la mitad de los españoles experimenta un sentimiento de identificación dual o compartida entre España y su Comunidad Autónoma. Este hecho se refuerza a partir de otras series de datos, como son: que la identificación y el nivel de orgullo entre España y las Comunidades Autónomas estén directamente correlacionados especialmente en los niveles más altos de la escala. Además, la misma tendencia se observa respecto del grado de confianza que tienen los españoles del Gobierno de España y el de las Comunidades Autónomas.

En definitiva, y España no es una excepción, la identidad se enfrenta constantemente a un mundo cada vez más mundializado, globalizado, etc., y lo local y sus diferentes tendencias tienen cada vez más limitaciones para des-

39. Salvando las distancias metodológicas, pero significativamente, según el barómetro del CIS de septiembre de 2003 referente a la opinión de los españoles sobre la democracia y la Constitución, respecto de la pregunta "¿Con qué organización del Estado está más de acuerdo?», siendo las categorías: «1. Gobierno central sin comunidades autónomas; 2 . Estado y CCAA; 3. Estado y CCAA con más competencias que ahora; 4. Estado y CCAA con posibilidad de independencia; 5 . NS/NC», los resultados más significativos en porcentajes fueron que el 51,1\% de la población señaló el Estado y las CCAA, y el 23\%, el Estado y las CCAA con más competencias. 


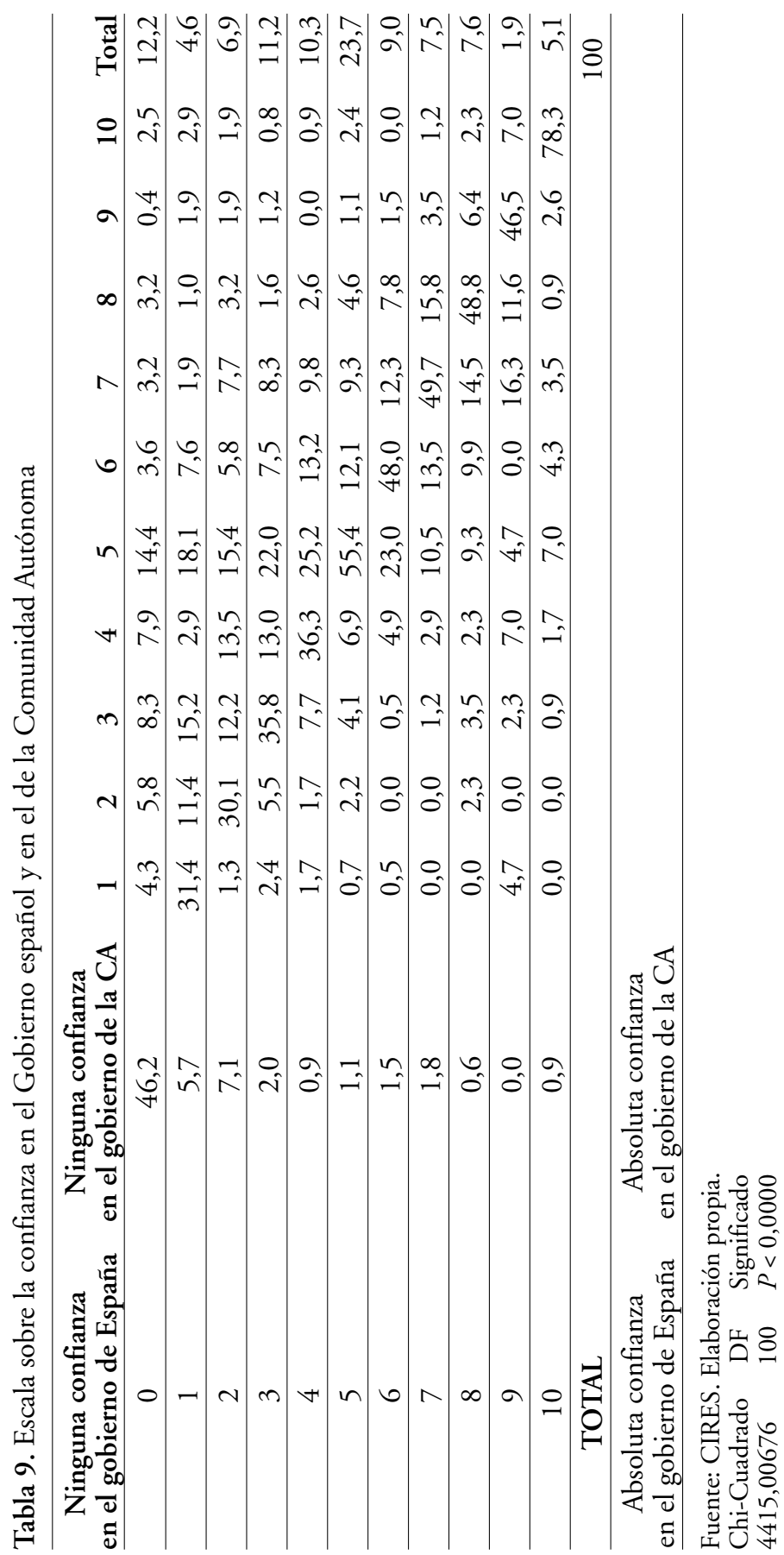


prenderse de lo global, aunque, por otra parte, es cierto que esta nueva era de la globalización tiende también a reforzar estructuras de viejas lealtades ${ }^{40}$, ya sean familiares, territoriales, étnicas o religiosas.

\section{Bibliografía}

AJA, E. (2003). El Estado Autonómico. Federalismo y hechos diferenciales. Madrid: Alianza. Ashcroft, B.; Ahluwalia, P. (2000). Edward Said: La paradoja de la identidad. Bellaterra: Universitat Autònoma de Barcelona.

ÄsNe SeRIERSTAD (2002). El librero de Kabul. Madrid: Maeva.

CASTELL, M. (1998). La era de la información. El poder de la identidad. Vol. 2. Madrid: Alianza.

CONNOR, W. (1998). Etnonacionalismo. Madrid: Trama.

CAMPo, S. DEL; NAVARro, M.; TezANOS, F. (1977). La cuestión regional española. Madrid: Edicusa.

ETZIONI, A. (2001). La tercera via hacia una buena sociedad: propuestas desde el comunitarismo. Madrid: Trotta.

García Ferrando, M. (1982). Regionalismo y autonomía en España (1976-1979). Madrid: CIS.

El País (2003) (Andalucía). Viernes, 24 de octubre.

Durkheim, E. (1968). Formas elementales de la vida religiosa. Buenos Aires: Schapire. ERIKSEN, T. H. (1993). Ethnicity and nationalism. Londres: Pluto Press.

García Ferrando, M.; López Aranguren, E.; Beltrán, M. (1994). La conciencia nacional y regional en la España de las autonomías. Madrid: CIS.

GELLNER, E. (1988). Naciones y nacionalismo. Madrid: Alianza.

Giddens, A. (1995). Modernidad e identidad del yo. Barcelona: Península.

GoyTisolo, L. (2004). «Referente cultural y sentimiento nacionalista». El País, lunes 9 de febrero.

GuibernAU, M. (1996). Los nacionalismos. Barcelona: Ariel.

HerRanZ, G. (1992). La vigencia del nacionalismo. Madrid: CIS.

- (1996). «Estructura social e identificación nacionalista en la España de los noventa». Revista Española de Investigaciones Sociológicas, núm. 76, p. 9-35.

HobSBAWn, E. J. (1992). Naciones y nacionalismos desde 1780. Barcelona: Crítica. Huntington, S. M. (1997). El choque de civilizaciones. Barcelona: Paidós.

40. Acertadamente, Castell, además de señalar la revitalización de los fundamentalismos y de los nacionalismos fuera del contexto del viejo esquema del Estado nación como formas de identidad cada vez más demandadas en un mundo globalizado e interconectado, añade que las identidades de base local tienen diferentes tendencias según quien lo interprete. Así, dice que mientras, «en los años recientes, Etzioni ve el renacimiento de la comunidad en buena medida de base local, Putnam observa la desintegración de la visión de Toqueville de una intensa sociedad civil en Norteamérica, donde las asociaciones de voluntariado han perdido miembros y actividad de forma sustancial durante la década de los ochenta", en CASTEll, M.; ob. cit., p. 83. Para el primer caso, véase, ETZIONI, A. (2001), La tercera vía hacia una buena sociedad: Propuestas desde el comunitarismo, Madrid: Trotta; para el segundo, Putnam, R. (1995), "Bowling alone: America’s declining social capital», Journal of Democracy, núm. 6 (1), p. 65-78, con la misma idea, en Solo en la bolera, Barcelona: Galaxia Gutemberg / Círculo de Lectores, 2002, y El declive del capital social, Barcelona: Galaxia Gutemberg / Círculo de Lectores, 2003. 
JiMÉNEZ BlanCO, J. y otros (1977). La conciencia regional en España. Madrid: CIS. Keating, M. (1996). Naciones contra el Estado. El nacionalismo de Cataluña, Québec y Escocia. Barcelona: Ariel.

KyMLICKA, W. (1996). Ciudadanía multicultural. Barcelona: Paidós.

LASCH, C. (1996). La revolución de las élites y traición a la democracia. Barcelona: Paidós. LÓPEZ ARANGUREN, E. (1983). La conciencia regional en el proceso autonómico español. Madrid: CIS.

López Aranguren, E.; GarCía FerRando, M. (1991). «Nacionalismo y regionalismo en la España de las Autonomías", en VidAl BeneYTO, J. (comp.). España a debate. La sociedad. Madrid: Tecnos.

MaAlouf, A. (2002). Identidades asesinas. Madrid: Alianza.

Moreno, L. (1997). La federalización de España. Madrid: Siglo XXI.

Morin, E. (2003). El método. La humanidad de la humanidad. La identidad humana. Madrid: Cátedra.

Pérez Agote, A. (1993). «Modelo fenomenológico-genético para el análisis comparativo de la dimensión política de las identidades colectivas en el Estado de las Autonomías", en BeramendI, J.G.; Maíz, R.; NúÑEZ, X. Nationalism in Europe. Past and present. Vol. I. Santiago de Compostela. Universidad de Santiago de Compostela, p. 307-323.

Putnam, R. (1995). «Bowling alone: America's declining social capital». Journal of Democracy, núm. 6, (1), p. 65-78.

- (2002). Solo en la bolera. Barcelona: Galaxia Gutemberg / Círculo de Lectores.

- (2003). El declive del capital social. Barcelona: Galaxia Gutemberg / Círculo de Lectores.

Rovira Y VirgiLI, A. (1980). Historia de los movimientos nacionalistas. 3 vol. Barcelona: Herder.

RuberT DE Ventós, X. (1994). Nacionalismos. El laberinto de la identidad. Madrid: Espasa-Calpe.

SMith, A. D. (1976). Las teorías del nacionalismo. Barcelona: Península.

- (1986). The ethnic origins of nations. Oxford: Blackwell.

- (1997). La identidad nacional. Madrid: Trama.

SOlÉ Tura, J. (1985). Nacionalidades y nacionalismos en España. Autonomías, federalismo, autodeterminación. Madrid: Alianza.

Touraine, A. (1995). «La formation du sujet», en Dubet, Wieviorka, M. (ed.). Penser le sujet. París: Fayard.

Virós, M. R.; CANAls, R. M.; PALlaréS, F. (1991). «Influència d'alguns factors sòciodemográfics i polítics. Perfil dels electorats», en L'electorat català a les eleccions autonòmiques de 1988: opinions, actituds i comportaments. Equip de Sociologia Electoral. Barcelona: Universitat Autònoma de Barcelona / Fundació Jaume Bofill. 